\title{
Utility of screening tools to differentiate beta thalassemia trait and iron-deficiency anemia - do they serve a purpose in blood donors?
}

\author{
Amanpreet Sundh ${ }^{1}$, Paramjit Kaur ${ }^{2}$, Anshu Palta ${ }^{3}$, Gagandeep Kaur ${ }^{2}$ \\ Department of Transfusion Medicine, ${ }^{1}$ All India Institute of Medical Sciences, New Delhi, ${ }^{2}$ Government Medical College and \\ Hospital, ${ }^{3}$ Department of Pathology, Government Medical College and Hospital, Chandigarh, India
}

p-ISSN 2287-979X / e-ISSN 2288-0011 https://doi.org/10.5045/br.2020.2020219 Blood Res 2020;55:169-174.

Received on August 26, 2020

Revised on September 4, 2020

Accepted on September 15, 2020

\author{
Correspondence to \\ Paramjit Kaur, M.D. \\ Department of Transfusion Medicine, \\ Government Medical College, Sector 32, \\ Chandigarh 160030, India \\ E-mail: paramjit.gp71@yahoo.com \\ (C) 2020 Korean Society of Hematology
}

\section{Background}

The aim of this study was to estimate the prevalence of the beta thalassemia trait (BTT) and differentiate it from iron-deficiency anemia (IDA) among blood donors.

\section{Methods}

A total of 1,000 samples from blood donors were subjected to complete hemogram with red blood cell indices. Further, Mentzer index (MI) was calculated for samples with mean corpuscular volume (MCV) below $80 \mathrm{fL}$ and mean corpuscular hemoglobin $(\mathrm{MCH})$ below $27 \mathrm{pg}$. Samples with Mentzer index $<12$ were subjected to naked-eye single-tube red cell osmotic fragility test (NESTROFT) followed by hemoglobin electrophoresis in positive cases. Serum ferritin was assessed in NESTROFT-negative cases.

\section{Results}

The prevalence of BTT among blood donors was $3.7 \%$ and that of microcytosis among donors was $8.6 \%$. The prevalence of BTT among microcytic donors was $41.8 \%$ while that among those with IDA was $11.6 \%$. A value of $\mathrm{MI}<13$ was highly sensitive in the diagnosis of BTT. MI >13 was found to have both high specificity and high sensitivity for diagnosing IDA.

\section{Conclusion}

A moderately high prevalence of BTT was observed among blood donors. Presently, no screening program is mandatory for screening of BTT among blood donors. Indices like $\mathrm{MCV}, \mathrm{MCH}$, and Mentzer Index were thus found to be effective to screen for BTT and IDA among blood donors, and NESTROFT was a cost-effective mass screening method to differentiate BTT and IDA.

Key Words Beta thalassemia trait, Blood donors, Mentzer index, NESTROFT, Iron deficiency anemia

\section{INTRODUCTION}

Thalassemias are a group of anemias resulting from genetic defects in the production of one or more of globin polypeptide chains of hemoglobin. These disorders lead to disruption in the production of alpha- or beta-globin polypeptide chains. Imbalance in the globin chain ratio and precipitation of unpaired chains lead to ineffective erythropoiesis and hemolytic anemia [1].

Thalassemias are inherited in an autosomal recessive pattern. The prevalence of thalassemias is particularly high in the Mediterranean region, the Indian subcontinent,
Southeast Asia, and West Africa [2]. Clinically, alpha and beta thalassemia may occur in varied genetic forms. Beta thalassemia trait (BTT) is the carrier state of beta thalassemia major, a disease that has grave economic implications for a developing country like India.

Worldwide, about 56,000 live births are diagnosed with a major thalassemia disorder each year; of these, approximately 30,000 are affected with beta thalassemia major [3]. The global prevalence of beta thalassemia carriers has been reported to be $1.5 \%$ [4]. The highest frequency is reported in Cyprus (14\%) followed by Sardinia (10.3\%) [5]. In India, the overall frequency is $4 \%$ [6]. Certain communities like Sindhis, Muslims, Kutchi Bhanushali, and some tribal groups 
have higher prevalence rates ranging from $8 \%$ to $10 \%$ [7]. Early diagnosis of BTT is vital to control the rising incidence of beta thalassemia major, a transfusion-dependent anemia associated with a wide gamut of complications. Screening for carriers of beta thalassemia at an appropriate age is an important tool to prevent thalassemia from occurring in children [8].

The present study aimed to determine the prevalence of BTT among blood donors and also to differentiate it from iron-deficiency anemia (IDA) in the healthy blood donor population using simple screening tools such as the Mentzer index (MI) and naked-eye single-tube red cell osmotic fragility test (NESTROFT).

\section{MATERIALS AND METHODS}

This was a prospective observational study conducted at the Department of Transfusion Medicine, in collaboration with the Department of Pathology, over a period of one-andhalf years. The study was approved by the Institutional Ethics Committee of the institution, and written informed consent was obtained from the donors. A total of 1,000 samples of both voluntary and replacement blood donors was studied to determine the prevalence of BTT. Donors deferred due to low hemoglobin level $(\mathrm{Hb}<12.5 \mathrm{~g} / \mathrm{dL})$ were also included in the study.

The inclusion criteria were voluntary and replacement blood donors aged 18-40 years weighing more than $45 \mathrm{~kg}$ and willing to participate in the study. Only first-time donors and those with a last donation more than two years prior to the study, but with a hemoglobin level above $12.5 \mathrm{gm} / \mathrm{dL}$, were enrolled. First-time donors deferred due to low hemoglobin levels (below $12.5 \mathrm{gm} / \mathrm{dL}$ ) were also included. Regular blood donors and donors deferred due to other reasons except low hemoglobin were excluded from the study. Blood samples of all donors eligible for the study were taken after donation of blood; blood samples of deferred donors were also taken. EDTA was used for obtaining a complete hemogram. Samples were analyzed using an automated cell counter within 24 hours of donation or sample collection.

Mean corpuscular volume (MCV) less than $80 \mathrm{fL}$ was considered as microcytosis. MI was calculated by dividing the MCV by the red blood cell count for all the samples having $\mathrm{MCV}<80 \mathrm{fL}$ and $\mathrm{MCH}<27 \mathrm{pg}$. The MI of each such sample was recorded, analyzed, and grouped under the following categories: MI >14, suggestive of IDA; MI 12-14, intermediate; $\mathrm{MI}<12$, suggestive of BTT.

Samples having $\mathrm{MI}<12$ and those with intermediate MI (range, 12-14) were subjected to NESTROFT [9]. Briefly, $2 \mathrm{~mL}$ of $0.36 \%$ buffered saline was taken in a test tube, and $2 \mathrm{~mL}$ of distilled water was taken in another test tube. After addition of $20 \mu \mathrm{L}$ of anticoagulated whole blood in each tube, both tubes were mixed well and left undisturbed for half an hour at room temperature. Subsequently, the contents were shaken and the tubes were held against a white paper on which a thin black line was drawn and observations were made regarding the visibility of the black line (yes or no). The tubes were then left undisturbed a further few hours and the contents again checked for

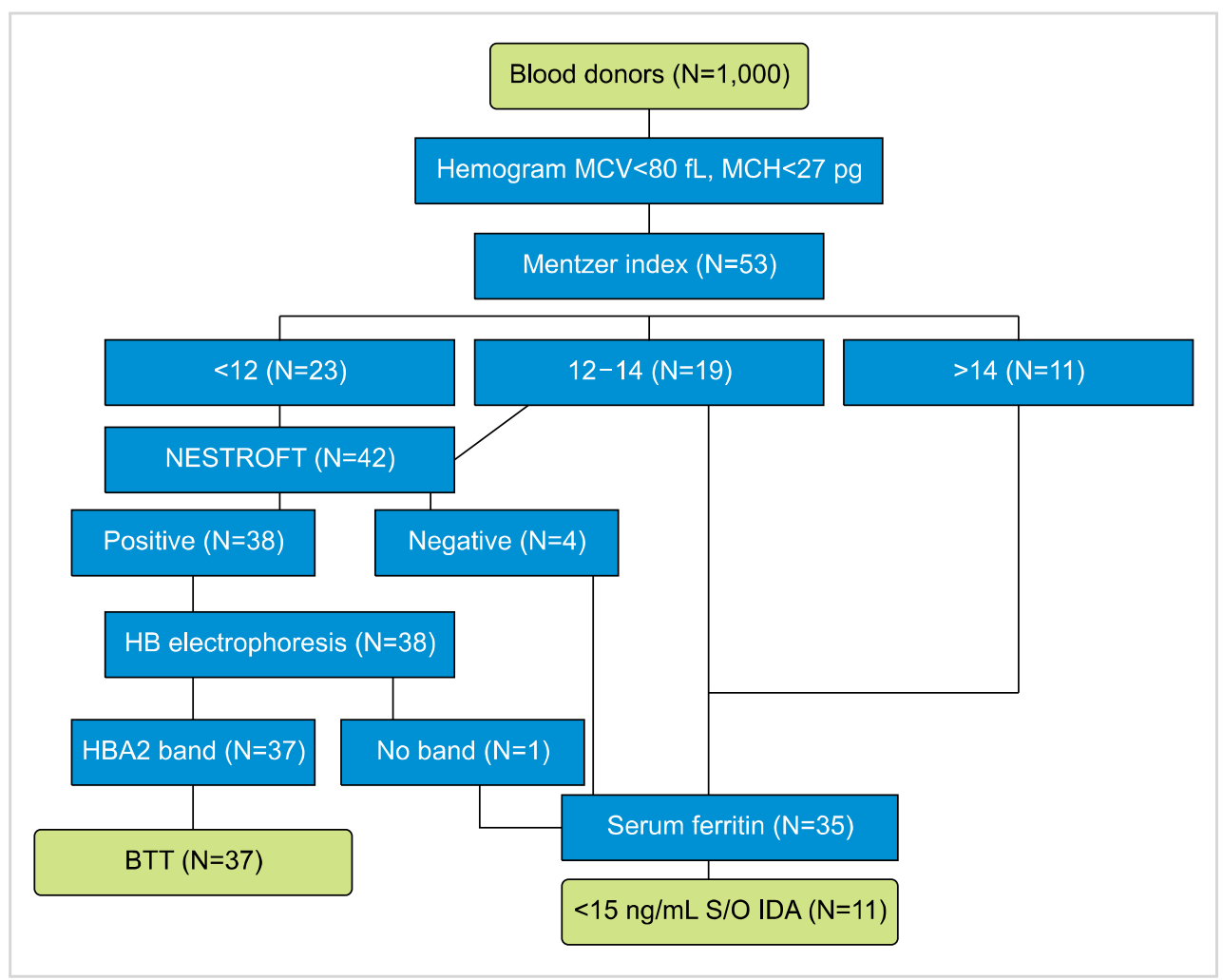

Fig. 1. Flow chart for defining of BTT and IDA and the number of cases in the study. Samples with normal serum ferritin and distinct $\mathrm{HbA} 2$ band on electrophoresis were defined as having BTT. Samples with serum ferritin below 15 $\mathrm{ng} / \mathrm{mL}$ were defined as having IDA [10].

Abbreviations: BTT, beta thalassemia trait; IDA, iron-deficiency anemia; $\mathrm{MCH}$, mean corpuscular hemoglobin; $\mathrm{MCV}$, mean corpuscular volume. 
hemolysis. The results were interpreted as NESTROFT positive or NESTROFT negative.

NESTROFT positive: Cases in which the black line was not visible or was hazy after 30 minutes of incubation at room temperature were considered positive. After prolonged incubation at room temperature, the presence of red cell sediments at the bottom of the tube and colorless saline in the remaining part of tube was observed.

NESTROFT negative: Cases in which the black line was clearly visible through the contents of the tube after 30 minutes of incubation at room temperature were considered negative. After prolonged incubation at room temperature, the presence of cell lysis in the form of uniformly pink distilled water, with no sedimentation of red cells at the bottom of the tube, was observed.

All the NESTROFT-positive cases were subjected to hemoglobin electrophoresis at alkaline $\mathrm{pH} 8.6$ and assessed for the presence of a band in the A2 region. All samples showing band in the A2 region on hemoglobin electrophoresis were considered as having a BTT.

Serum ferritin was assessed using enzyme-linked immunosorbent assay (ELISA; Orgentec Diagnostica GmbH) in cases where MI $>14$ and where there was indeterminate MI (range, 12-14) as well as in all NESTROFT-negative cases. This was also assessed in those with RBC indices highly suggestive of BTT and were NESTROFT positive, but had no band in the $\mathrm{A} 2$ region on hemoglobin electrophoresis. This was done to rule out the concomitant presence of IDA.

Levels of serum ferritin below $15 \mathrm{ng} / \mathrm{mL}$ were considered as IDA (Fig. 1) [10].

\section{Statistical analysis}

SPSS (SPSS Inc., Chicago, IL, USA) for Windows version 17.0 was used for data analysis. Prevalence rates were calculated and compared according to the type of donor, age group, gender, place of residence, religion, and presence or absence of family history of consanguinity and family history of thalassemia. Continuous data were analyzed in

\begin{tabular}{lcc}
\hline \multicolumn{3}{l}{ Table 1. Prevalence of BTT among blood donors. } \\
\hline & Prevalence of BTT (\%) & $P$ \\
\hline Overall & 3.7 & \\
Voluntary donors & 2.48 & $<0.01$ \\
Replacement donors & 13.04 & $<0.01$ \\
Accepted donors & 1.6 & \\
Deferred donors & 37.2 & $>0.05$ \\
Males & 3.38 & \\
Females & 7.23 & $>0.01$ \\
18-30 yr & 4.3 & $>0.05$ \\
30-40 yr & 0.6 & \\
Urban background & 2.8 & $<0.01$ \\
Rural background & 4.8 & \\
Consanguinity & 64.2 & \\
No consanguinity & 2.83 & \\
\hline
\end{tabular}

Abbreviation: BTT, beta thalassemia trait. the form of mean and standard deviation. Differences were evaluated using the Chi-square test and Student's t-test. A $P$-value of $<0.05$ was considered statistically significant.

\section{RESULTS}

Out of 1,000 blood donors, 885 (88.5\%) volunteered while $115(11.5 \%)$ were replacement donors. Among voluntary donors, 815 (92.1\%) were males and $70(7.9 \%)$ were females. There were 102 (88.69\%) males and $13(11.31 \%)$ females among replacement donors. Majority of donors (941, 94.1\%) were accepted donors while 59 (5.9\%) were deferred donors. Of the 59 deferred donors, $42(71.2 \%)$ were males and 17 (28.8\%) were females. The mean age of donors was 25.3 years, and median age was 24 years. The maximum number of donors $(636,63.6 \%)$ were in the age group of 18-25 years and least $(2.9 \%)$ were in the age group of $36-40$ years. The prevalence of BTT among blood donors is shown in Table 1.

The overall prevalence of BTT among blood donors was $3.7 \%$. The prevalence of BTT varied from $1.53 \%$ to $4.25 \%$ across various religious groups. The majority of the donors were from Punjab, Chandigarh, and Haryana, in descending order. The highest prevalence of BTT was found in Delhi (8.6\%) followed by Punjab (5.2\%). Chandigarh had a prevalence of $2.2 \%$, while that in Haryana was $2.7 \%$.

Overall prevalence of microcytosis in blood donors was found to be $8.6 \%$. Prevalence of microcytosis in voluntary donors was $7.2 \%$, while it was $19.1 \%$ in replacement donors $(P<0.01)$. Of the 941 accepted donors, $45(4.8 \%)$ were found to be microcytic (MCV $<80 \mathrm{fL}$ ). Forty-one $(69.4 \%)$ out of 59 deferred donors were found to be microcytic. The difference was highly statistically significant $(P<0.01)$.

Of the 86 donors with microcytosis, $41(47.6 \%)$ were found to be anemic $(\mathrm{Hb}<12.5 \mathrm{~g} / \mathrm{dL})$ while $45(52.4 \%)$ microcytic donors had hemoglobin levels above $12.5 \mathrm{~g} / \mathrm{dL}$. The prevalence of BTT among microcytic donors was $41.8 \%$ and that of IDA among microcytic donors was $11.6 \%$ (Table 2). Out of the 86 microcytic donors, MI was found to be applicable $(\mathrm{MCV}<80 \mathrm{fL}$ and $\mathrm{MCH}<27 \mathrm{pg})$ in 53 donors. Out of these 53 donors, 23 donors had $\mathrm{MI}<12$, 19 donors had MI=12-14, and 11 donors had MI $>14$ (Table 3).

On further analysis of $\mathrm{MI}$ in the indeterminate range of

Table 2. Prevalence and type of anemia among microcytic blood donors.

\begin{tabular}{|c|c|c|c|c|c|}
\hline \multirow[t]{5}{*}{$\begin{array}{c}\text { Microcytic } \\
\text { donors }\end{array}$} & \multirow[t]{5}{*}{86} & $\begin{array}{c}\mathrm{Hb}>12.5 \\
\mathrm{~g} / \mathrm{dL}\end{array}$ & $45(52.4 \%)$ & $\begin{array}{l}\text { Normal } \\
\text { BTT }\end{array}$ & $\begin{array}{l}30 \\
15\end{array}$ \\
\hline & & $\mathrm{Hb}<12.5$ & $41(47.6 \%)$ & BTT & 21 \\
\hline & & $\mathrm{g} / \mathrm{dL}$ & & IDA & 10 \\
\hline & & & & Both & 1 \\
\hline & & & & None & 9 \\
\hline
\end{tabular}

Abbreviations: BTT, beta thalassemia trait; IDA, iron-deficiency anemia. 
Table 3. Association of different MI values with type of anemia.

\begin{tabular}{lrrcc}
\hline & BTT & IDA & Others & Total \\
\hline $\mathrm{Ml}<12$ & 23 & 0 & 0 & 23 \\
$\mathrm{Ml} 12-14$ & 14 & 1 & 4 & 19 \\
$\mathrm{MI}>14$ & 0 & 10 & 1 & 11 \\
Total & 37 & 11 & 5 & 53
\end{tabular}

Abbreviations: BTT, beta thalassemia trait; IDA, iron-deficiency anemia; $\mathrm{MI}$, Mentzer index.

Table 4. Comparison of hematological parameters in donors with BTT and non-BTT.

\begin{tabular}{lccc}
\multicolumn{1}{c}{ Parameter } & $\begin{array}{c}\mathrm{BTT} \\
(\mathrm{N}=37)\end{array}$ & $\begin{array}{c}\text { Non-BTT } \\
(\mathrm{N}=963)\end{array}$ & $P$ \\
\hline $\mathrm{Hb}(\mathrm{g} / \mathrm{dL})$ & $12.3 \pm 0.57$ & $13.9 \pm 1.07$ & $<0.0001$ \\
$\mathrm{MCV}(\mathrm{fL})$ & $70.4 \pm 2.84$ & $87.4 \pm 6.13$ & $<0.0001$ \\
$\mathrm{MCH}(\mathrm{pg})$ & $23.7 \pm 2.43$ & $29.7 \pm 1.65$ & $<0.0001$ \\
$\mathrm{MCHC}(\%)$ & $30.2 \pm 0.81$ & $32.1 \pm 1.48$ & $<0.0001$ \\
$\mathrm{TLC}\left(\times 10^{3} / \mu \mathrm{L}\right)$ & $6.26 \pm 1.86$ & $6.12 \pm 1.77$ & 0.6376 \\
$\mathrm{RBC}\left(\times 10^{6} / \mu \mathrm{L}\right)$ & $5.89 \pm 0.34$ & $4.68 \pm 0.47$ & $<0.0001$ \\
$\mathrm{PCV}(\%)$ & $38.9 \pm 2.02$ & $42.1 \pm 3.28$ & $<0.0001$ \\
$\mathrm{RDWC}(\%)$ & $14.6 \pm 0.66$ & $14.5 \pm 0.43$ & 0.1756 \\
Platelets $\left(\times 10^{3} / \mu \mathrm{L}\right)$ & $223 \pm 54.2$ & $250 \pm 67.4$ & 0.163 \\
\hline
\end{tabular}

Abbreviations: $\mathrm{BTT}$, beta thalassemia trait; $\mathrm{Hb}$, hemoglobin; $\mathrm{MCH}$, mean corpuscular hemoglobin; MCHC, mean corpuscular hemoglobin concentration; $\mathrm{MCV}$, mean corpuscular volume; $\mathrm{PCV}$, packed cell colume; RBC, red blood cell; RDWc, red cell distribution width; TLC, total leucocyte count.

12-14, it was observed that MI $<13$ was highly sensitive for the diagnosis of BTT. While specificity of MI $<13$ was $68.7 \%$, its sensitivity was $100 \%$. Its positive predictive value was $88 \%$ and negative predictive value was $100 \%$. MI $>13$ was found to have both high specificity and sensitivity for diagnosing IDA. It showed a sensitivity of $90.9 \%$ and a specificity of $97.6 \%$. The positive predictive value for $\mathrm{MI}>13$ was $90.9 \%$ and negative predictive value was $97.6 \%$.

Analysis and comparison of the mean values of various hematological parameters in BTT and non-BTT donors were carried out. Mean RBC count was significantly higher in the BTT group $\left(5.89 \times 10^{6} / \mu \mathrm{L}\right)$ compared to the non-BTT group $\left(4.68 \times 10^{6} / \mu \mathrm{L} ; P<0.0001\right)$, while mean hemoglobin $(12.3$ $\mathrm{g} / \mathrm{dL}$ ) was slightly less in BTT cases when compared to non-BTT cases $(13.9 \mathrm{~g} / \mathrm{dL} ; P<0.001)$. Similarly MCV, $\mathrm{MCH}$, and $\mathrm{MCHC}$ were significantly reduced in BTT cases when compared to non-BTT cases $(P<0.0001)$, as shown in Table 4.

Mean hemoglobin was significantly lowered in IDA (11.5 $\mathrm{g} / \mathrm{dL})$ with respect to that in BTT $(12.3 \mathrm{~g} / \mathrm{dL} ; P<0.001)$, as shown in Table 5 . MCV and MCH means were significantly reduced in BTT as compared to IDA $(P<0.0001)$. RBC count was significantly higher in BTT $\left(5.89 \times 10^{6} / \mu \mathrm{L}\right)$ as compared to IDA $\left(4.60 \times 10^{6} / \mu \mathrm{L} ; P<0.0001\right)$. Another significant observation was made in the difference of means of RDWc
Table 5. Comparison of hematological parameters in donors with BTT and IDA.

\begin{tabular}{lcrc}
\multicolumn{1}{c}{ Parameter } & $\mathrm{BTT}(\mathrm{N}=37)$ & $\mathrm{IDA}(\mathrm{N}=11)$ & $P$ \\
\hline $\mathrm{Hb}(\mathrm{g} / \mathrm{dL})$ & $12.3 \pm 0.57$ & $11.5 \pm 0.56$ & $<0.001$ \\
$\mathrm{MCV}(\mathrm{fL})$ & $70.4 \pm 2.84$ & $76.4 \pm 1.44$ & $<0.0001$ \\
$\mathrm{MCH}(\mathrm{pg})$ & $23.7 \pm 2.43$ & $27.4 \pm 1.12$ & $<0.0001$ \\
$\mathrm{MCHC}(\%)$ & $30.2 \pm 0.81$ & $31.2 \pm 1.67$ & 0.0085 \\
$\mathrm{TLC}\left(\times 10^{3} / \mu \mathrm{L}\right)$ & $6.26 \pm 1.86$ & $5.90 \pm 1.94$ & 0.5794 \\
$\mathrm{RBC}\left(10^{6} / \mu \mathrm{L}\right)$ & $5.89 \pm 0.34$ & $4.60 \pm 0.53$ & $<0.0001$ \\
$\mathrm{PCV}(\%)$ & $38.9 \pm 2.02$ & $35.1 \pm 1.72$ & $<0.0001$ \\
$\mathrm{RDWC}(\%)$ & $14.6 \pm 0.66$ & $16.1 \pm 1.36$ & $<0.0001$ \\
Platelets $\left(\times 10^{3} / \mu \mathrm{L}\right)$ & $223 \pm 54.2$ & $192 \pm 19.1$ & 0.07 \\
MI & $11.4 \pm 0.75$ & $17.0 \pm 2.05$ & $<0.0001$ \\
S. ferritin $(\mathrm{ng} / \mathrm{mL})$ & $150 \pm 73.8(\mathrm{~N}=14)$ & $12.9 \pm 1.13$ & $<0.0001$ \\
\hline
\end{tabular}

Abbreviations: $\mathrm{BTT}$, beta thalassemia trait; $\mathrm{Hb}$, hemoglobin; $\mathrm{MCH}$, mean corpuscular hemoglobin; $\mathrm{MCHC}$, mean corpuscular hemoglobin concentration; $\mathrm{MCV}$, mean corpuscular volume; MI, Mentzer index; PCV, packed cell colume; RBC, red blood cell; RDWc, red cell distribution width; $S$. ferritin, serum ferritin; TLC, total leucocyte count.

between BTT and IDA. RDWc mean was significantly higher in IDA (16.1\%) as compared to RDWc mean in BTT $(14.6 \%$; $P<0.0001)$. High RBC count and low hemoglobin values were significantly and positively associated with the incidence of BTT.

NESTROFT was found to be applicable in 42 cases, out of which 38 were positive and 4 were negative. One case, out of 38 NESTROFT-positive cases, was found to be negative on $\mathrm{Hb}$ electrophoresis. Only positive predictive value for NESTROFT could be derived which was $97.3 \%$.

\section{DISCUSSION}

The overall prevalence of BTT in our donor population was $3.7 \%$. Other studies from India have shown varied prevalence of BTT ranging from $1.53 \%$ to $9.59 \%$ [6, 11-16]. A study conducted in school children found the prevalence of BTT to be $4.05 \%$ [6]. Another study from the southern part of India conducted in pregnant females reported a prevalence of $8.5 \%$ [13]. India being a country with vast ethnic diversity could be the reason for the wide variation in prevalence. Moreover, target groups and methods employed for estimation of prevalence were also different in these studies.

In a study conducted on blood donors in Malaysia, the prevalence of BTT was reported to be 5\% [17]. In another study conducted in Egyptian blood donors to differentiate between BTT and IDA, the prevalence of BTT was found to be $6 \%$ [18]. A literature report from Pakistan found 73 (14.5\%) out of 503 subjects to be beta thalassemia carriers, using NESTROFT as differentiating index between BTT and IDA. This discrepancy in results could be due to the different study populations as the authors included only subjects with microcytosis [19]. 
We found a high prevalence of BTT in the age group of $25-30$ years $(5.4 \%)$ followed by $18-25$ years (3.9\%). Some studies have reported comparable prevalence across all age groups [12]. Our study population comprised $83.7 \%$ donors younger than 30 years of age; hence, prevalence in other age groups could not be ascertained. Although $7.23 \%$ of females were carriers of BTT compared to $3.38 \%$ males, we do not generalize these figures to the whole population due to small number of female donors in our study.

A highly significant difference was found in prevalence among deferred donors (37.2\%) in comparison to accepted donors $(1.6 \%)$. The mean hemoglobin level of donors with BTT was $12.3 \%$, which justifies the observation of using the cutoff for accepting donation as $12.5 \mathrm{~g} / \mathrm{dL}$. Wide variation was present between frequencies of BTT according to the states of residence of the donor, but these were not found to be statistically significant $(P>0.05)$. State-wise prevalence for the state of Punjab (5.2\%) which represented 36.5\% of our study population was comparable with the study conducted by Kumar et al. (4.4\%) and Mohanty et al. (3.96\%) $[16,11]$. A higher prevalence in Punjab has been reported by Chatterjee et al. (11.79\%) [12]. They used Bayesian estimates in assessing the prevalence of BTT. Our results were similar to those of Kumar et al. [16] in terms of BTT prevalence in Haryana and Himachal Pradesh.

We found a significant association between a history of consanguinity and BTT, but other authors have reported different results. Our finding of a significant association between the two is likely to be a result of the concomitant presence of associated family history of thalassemia in one-third of the donors, owing to the history of consanguineous marriage in the family. Religion-wise prevalence did not show any significant difference, as reported in other studies $[11,12,16]$.

In our study population, $8.6 \%$ of the blood donors were found to be microcytic. Significant association was found between replacement donors and prevalence of microcytosis and also between deferred donors and microcytosis $(P<$ 0.01). Another significant observation was that $47.6 \%$ of the 86 donors with microcytosis were found to be anemic, with $24.4 \%$ having IDA, $51.2 \%$ having BTT, and $2.4 \%$ having concomitant BTT and IDA; in 21.9\% donors, neither BTT nor IDA could be confirmed. In a study from the northern part of India, the authors found prevalence of microcytosis in blood donors to be $5.4 \%$, and out of these microcytic donors they reported $52 \%$ as having IDA, $36 \%$ as having BTT, $8 \%$ as having both the conditions and, $4 \%$ as having neither condition [14]. The majority of our donors belonged to plains of Punjab and Haryana, where IDA is less prevalent as compared to the donors from hilly regions of India, like Uttarakhand, where the prevalence of IDA is more. Another recent study from Gujarat reported $14.75 \%$ prevalence of microcytosis in blood donors [15]. Soliman et al. [18] reported prevalence of microcytosis to be $10.5 \%$ in healthy Egyptian adult blood donors.

The hematological parameters of BTT donors from our study were comparable with those found in other studies, although variations existed in hematological parameters of donors with IDA in our study and the other three studies, which could be due to the small sample size of donors with IDA in our study $[14,18,19]$.

We evaluated MI cut-off value of 13 as a discriminating factor to differentiate between cases of BTT and IDA. MI $<13$ was found to be significantly associated with BTT, with $100 \%$ sensitivity and $68.7 \%$ specificity. MI $>13$ was found to be significantly associated with IDA, with a specificity of $97.6 \%$ and sensitivity of $90.9 \%$. Tiwari et al. [14] found sensitivity and specificity of $100 \%$ and $72 \%$, respectively, in case of IDA and $72 \%$ and $100 \%$, respectively, in case of BTT. In case of NESTROFT, we could only derive the positive predictive value, due to our study limitation, and found it to be $97.3 \%$.

High-performance liquid chromatography (HPLC) is used to screen patients for hemoglobin disorders. In a large prospective study from eastern part of India conducted over a period of 10 years, BTT was the most common hemoglobin abnormality (4.6\%) [20]. Some authors have recommended a screening algorithm for blood donors that includes HPLC analysis of microcytic donors with plasma ferritin levels above $15 \mathrm{ng} / \mathrm{mL}$ [21]. However, we could not perform HPLC in our donor population.

Our study has a few limitations. According to our study methodology, we could not perform $\mathrm{Hb}$ electrophoresis in all the cases in which NESTROFT was done due to which performance characteristics of NESTROFT could not be evaluated and compared. Moreover, we could not estimate $\mathrm{HbA} 2$ levels by HPLC, and DNA profiling could not be done due to financial constraints and lack of infrastructure.

In conclusion, we found moderately high prevalence of BTT among the blood donor population, suggestive of an increased risk of beta thalassemia major incidence in the near future. Currently, no screening program is mandatory for screening of BTT among blood donors, and donor screening is only done for anemia using hemoglobin estimation in blood banks. Based on the findings of this study, screening of blood donors for BTT and differentiating it from IDA is proposed using indices like $\mathrm{MCV}, \mathrm{MCH}, \mathrm{MI}$, and NESTROFT, which have the advantage of being cost-effective and, thus, an advantage for developing countries like India where BTT and IDA are prevalent. An algorithmic approach can be devised to identify blood donors with BTT and differentiate it from IDA so that the blood donor is appropriately guided for counseling or iron therapy, respectively.

\section{Authors' Disclosures of Potential Conflicts of Interest}

No potential conflicts of interest relevant to this article were reported. 


\section{ACKNOWLEDGMENTS}

The study was approved by the institutional research and ethics committee, and informed written consent was taken from all blood donors who participated in the study.

\section{REFERENCES}

1. Borgna-Pignatti C, Galanello R. Thalassemias and related disorders: quantitative disorders of hemoglobin synthesis. In: Greer JP, Foerster J, Rodgers GM, Paraskevas F, Glader B, Means RT, eds. Wintrobe's clinical hematology. 12th ed. Philadelphia, PA: Lippincott Williams \& Wilkins, 2009:1082-131.

2. Weatherall DJ. The thalassemias: disorders of globin synthesis. In: Kaushansky K, Lichtman M, Beutler E, Kipps T, Prchal J, Seligsohn U, eds. Williams hematology. 8th ed. New York, NY: McGraw-Hill, 2010:675-708.

3. Modell B, Darlison M. Global epidemiology of haemoglobin disorders and derived service indicators. Bull World Health Organ 2008;86:480-7.

4. Vichinsky EP. Changing patterns of thalassemia worldwide. Ann N Y Acad Sci 2005;1054:18-24.

5. Flint J, Harding RM, Boyce AJ, Clegg JB. The population genetics of the haemoglobinopathies. Baillieres Clin Haematol 1998;11: 1-51.

6. Madan N, Sharma S, Sood SK, Colah R, Bhatia LH. Frequency of $\beta$-thalassemia trait and other hemoglobinopathies in northern and western India. Indian J Hum Genet 2010;16:16-25.

7. Mehta BC, Dave VB, Joshi SR, Baxi AJ, Bhatia HM, Patel JC. Study of hematological and genetical characteristics of Cutchhi Bhanushali community. Indian J Med Res 1972;60:305-11.

8. Verma IC, Saxena R, Kohli S. Past, present \& future scenario of thalassaemic care \& control in India. Indian J Med Res 2011;134 507-21.

9. Kattamis C, Efremov G, Pootrakul S. Effectiveness of one tube osmotic fragility screening in detecting beta-thalassaemia trait. J Med Genet 1981;18:266-70.

10. Means RT, Glader B. Anemia: general considerations. In: Greer JP, Arber DA, Glader B, et al, eds. Wintrobe's clinical hematology. 13th ed. Philadelphia, PA: Lippincott Williams \& Wilkins, 2014:587-616.

11. Mohanty D, Colah RB, Gorakshakar AC, et al. Prevalence of $\beta$-thalassemia and other haemoglobinopathies in six cities in India: a multicentre study. J Community Genet 2013;4:33-42.

12. Chatterjee N, Mishra A, Soni R, Kulkarni H, Mamtani M, Shrivasatava M. Bayesian estimates of the prevalence of $\beta$-thalassemia trait in voluntary blood donors of central India: a survey. Hemoglobin 2010;34:548-60.

13. Kulkarni P, Masthi NR, Niveditha S, Suvarna R. The prevalence of the beta thalassemia trait among the pregnant women who attended the ANC Clinic in a PHC, by using the NESTROF Test in Bangalore, Karnataka. J Clin Diagn Res 2013;7:1414-7.

14. Tiwari AK, Chandola I, Ahuja A. Approach to blood donors with microcytosis. Transfus Med 2010;20:88-94.

15. Tailor HJ, Patel PR. A prospective study of hidden cases of beta thalassemia trait in voluntary blood donors at tertiary care hospital of South Gujarat. Trop J Pathol Microbiol 2019;5:580-4.

16. Kumar R, Gupta S, Jindal A, Kakkar S, Kaur A. Screening of $\beta$-thalassemia trait and other hemoglobinopathies among blood donors in Punjab. Int J Med Public Health 2015;5:106-9.

17. Rosline H, Ahmed SA, Al-Joudi FS, Rapiaah M, Naing NN, Adam NA. Thalassemia among blood donors at the Hospital Universiti Sains Malaysia. Southeast Asian J Trop Med Public Health 2006;37:549-52.

18. Soliman AR, Kamal G, Elsalakawy Walaa A, Sallam Mohamed TH. Blood indices to differentiate between $\beta$-thalassemia trait and iron deficiency anemia in adult healthy Egyptian blood donors. Egypt J Haematol 2014;39:91-7.

19. Sumera A, Ahmed S, Adnan Ali SM, Khanani R. Evaluation of NESTROFT as a marker of differentiation between $\beta$-thalassemia trait \& iron deficiency anemia. Int J Collab Res Intern Med Public Health 2012;4:1560-6.

20. Mondal SK, Mandal S. Prevalence of thalassemia and hemoglobinopathy in eastern India: A 10-year high-performance liquid chromatography study of 119,336 cases. Asian J Transfus Sci 2016; 10:105-10.

21. Tiwari AK, Chandola I. Comparing prevalence of iron deficiency anemia and beta thalassemia trait in microcytic and non-microcytic blood donors: suggested algorithm for donor screening. Asian J Transfus Sci 2009;3:99-102. 